\title{
Self-Harm Behaviour in Adolescents: Body Image and Self-Esteem
}

\author{
Vesile Oktan \\ Department of Educational Sciences, Karadeniz Technical University, Trabzon, Turkey
}

\begin{abstract}
This research aimed to reveal the relationship between self-harm behaviour, body image, and self-esteem, and examined whether there was a difference between the body image and self-esteem of the adolescents who exhibited self-harm behaviour and those who did not. The study was conducted with the participation of 263 high school students - 143 females (54.3\%) and 120 males $(45.6 \%)$ - who studied in various high schools in the Trabzon province, Turkey. The students' ages ranged from 15 to 18 ; the mean age was 17.02 $(S D=1.59)$. The research was conducted using the Inventory of Statements about Self-Injury, the Body Perception Scale, the Rosenberg Self-Esteem Scale, and a personal information form. The research concluded that there was a significant relationship between body image and self-esteem of the adolescents, and that body image and self-esteem were the significant regressors of self-harm behaviour.
\end{abstract}

Keywords: self-harm behaviour, body image, self-esteem

Self-harm behaviour (SHB) is defined as the intentional physical harming of one's own body (injuring, cutting the skin, wound-excoriation, and so on) without suicidal intention, social amusement purpose, or alcohol and drug overdose (Brausch, Decker, \& Hadley, 2011; Svec, Vandenburg, Jack, Toland, \& Barerra, 1989; Tresno, Ito, \& Mearns, 2012). SHB usually begins in adolescence and is more commonly observed in adolescence and young adult ages than in adults (Claassen et al., 2006). SHB is a public health problem that should be studied (Timson, Priest, \& Clark-Carter, 2012) and handled professionally from many points of view (Turp, 1999; Shaffer \& Jacobson, 2009). In non-clinical adolescent samples, frequencies varied between $12 \%$ and $23 \%$, and in clinical adolescent samples the frequencies have been reported to be as high as $68 \%$ (Oktan, 2014).

Unlike in clinical samples, the behaviour is most likely underreported in community samples because of its secretive nature (Andover, Pepper, \& Gibb, 2007). Therefore, there is limited information about the underlying causes of SHB in social samples. The previous studies indicated that the most important reason for SHB

ADDRESS FOR CORRESPONDENCE: Karadeniz Technical University, Faculty of Fatih Education, Department of Educational Sciences, Psychological Counselling and Guidance Program, 61335 Sögütlü/Trabzon, Turkey. Email: vesile@ktu.edu.tr 
is to reduce the effect of the undesired negative feelings, depression, self-anger, and strain (Gratz, Conrad, \& Roemer, 2002; Rodham, Hawton, \& Ewans, 2004; Skegg, 2005; Webb, 2002). Adolescence is a period during which numerous major psychological disorders, such as depression and eating disorders, may emerge. In addition, first attempts of SHB are usually reported at this age. It is also believed that during adolescence, the body becomes more salient to one's self-conception, and therefore it may represent a mediator through which psychological distress is expressed (Muehlenkamp \& Brausch, 2012).

Orbach (1996) suggested that having negative body attributes and losing interest in preserving the body image and the body increased individuals' suicidal tendencies. The same researcher also asserted that individuals with negative body attributes were increasingly harming their bodies. In such cases, these individuals showed contempt and disrespect for their own bodies and were disassociated from them (Nelson \& Muehlenkamp, 2012). Body conception deviations (body image distortions), dissatisfaction with one's body, negative experiences and evaluations represent perceptual distortions associated with body appearance and/or physical appearance (Cash, 2002).

Only a limited number of studies have analysed the relationship between negative body image and SHB. Ross, Heath, and Toste (2009) revealed that regardless of the gender, the individuals who exhibited SHB had body images that were more negative than the individuals who did not. Walsh (2006) indicated that a person's bodily attributes and their relationship with their body play a central role in their beginning to exhibit SHB and their continuing this behaviour. Brunner et al. (2007) revealed that adolescents with a history of SHB were not satisfied with their bodies, and the individuals who were not satisfied with their bodies showed much more risk for the repetition of this behaviour. Thus, there is a growing theoretical consensus that body image may be an important factor that should be taken into consideration when examining the risk for SHB.

The triggering event for many adolescents who exhibit SHB is conflict with peers and parents and having a perception of being rejected by them $(\mathrm{Ng}, 1998)$. According to the literature, these adolescents are typically perfectionists: they are not satisfied with their physical appearance and they have trouble in controlling and expressing their feelings (Kemperman et al., 1997). They also have a distorted self-perception (Kemperman et al., 1997) and a low level of self-esteem (Claes, Houben, Vandereycken, Bijttebier, \& Muehlenkamp, 2010; Cawood \& Huprich, 2011; Lundh, Karim, \& Quilisch, 2007). A study conducted by Laye-Gindhu and Schonerd-Reichl (2005) with high school students revealed that adolescents who exhibited SHB had negative self-esteem. On the other hand, a low level of self-esteem as a result of body dissatisfaction was indicated to be a mediator for SHB (Low, Jones, MacLeod, Power, \& Duggan, 2000). As self-esteem is an important concept in adolescence that changes during that time (Steinberg, 2013), the present study emphasised the requirement for examining SHB in terms of self-esteem. Therefore, this research aimed to reveal the relationship between SHB, body image, and selfesteem, and sought to elucidate which SHB was exhibited most, and also examined whether there was a difference between the body image and self-esteem of the adolescents who exhibited self-harm behaviour and those who did not. The hypotheses of the present study are as follows: 
H1. There is a significant relationship between SHB, body image, and self-esteem.

H2. Body image and self-esteem are significant regressors in adolescents.

H3. There is a difference between the body image and self-esteem of the adolescents who exhibit SHB and those who do not.

\section{Method}

\section{Participants}

The subjects for this survey were students in Grades 9, 10, and 11 from four different high schools in Trabzon, Turkey. The sample comprised 263 students who volunteered for the study -143 females $(54.3 \%)$ and 120 males $(45.6 \%)-$ attending four high schools in the city centre from whom permission was received to collect data. Students' ages ranged from 15 to 18 ; the mean age was 17.02 $(S D=1.59)$. Particular care was paid not to select adolescents previously diagnosed with a psychiatric disorder. This question was asked of students on the personal information form. In the present study, 300 questionnaires were administered. Data collected from four students diagnosed with a psychiatric disorder and data from 33 students with incomplete forms were excluded from the analysis.

\section{Instruments}

The Inventory of Statements About Self-Injury (ISAS; Klonsky \& Glenn, 2009), Body Perception Scale (BPS; Secord \& Jourard, 1953), Rosenberg Self-Esteem Scale (RSES; Rosenberg, 1965) and a personal information form were administered to students divided into groups in class by the researcher. Prior to practice, adequate information was provided on the objectives of research and the ways to respond to measurement tools.

The Inventory of Statements About Self-Injury. The main function of the ISAS is to extensively evaluate self-harm behaviours in adolescents without 'suicidal intentions'. With this inventory, not only the functions of these behaviours, but also 12 differing types can be evaluated. This inventory was developed by Klonsky and Glenn (2009) and transcribed into Turkish by Bildik, Somer, Kabukcu Basay, Basay, and Ozbaran (2012). It comprises two sections. Section I (Behaviours) inquires into the lifelong frequency of 12 types of 'non-suicidal and deliberate' SHB. Participants in this study who exhibited at least one SHB in the first section of the inventory were then directed to Section II (Functions). This section examined 13 SHB functions through 39 questions with two separate subscales (autonomic and social functions). Reliability studies of Section I showed a high internal consistency score $(\alpha=0.79)$ with self-harm behaviours that were examined collectively in the first section of inventory. Section I displayed the expected level and direction of validity. Based on validity studies, construct validity was evaluated and the validity of the first section of inventory was supported by the findings. Reliability studies of Section II gave a total internal consistency score of $\alpha=0.93$ for total functions. In test-retest reliability study of the inventory, the correlation between two practices was found to be $r=.64$ for total functions. The relationship between the total and subscale scores of Functions of ISAS along with the measures that evaluated the expected clinical features was found to be quite strong in validity studies of Section II. 
Considered overall in the context of construct validity, research findings indicated that use of ISAS in the examination of self-harm behaviours and in the clarification of its functions for Turkish adolescent samples would give valid and reliable results (Bildik et al., 2012).

Body Perception Scale. The BPS was used to determine body perceptions (images) of participants. This scale was developed by Secord and Jourard (1953) and adapted into Turkish by Hovardaoğlu (1993). The scale consists of 40 articles that refer to each organ or their functions. Hovardaoğlu (1993) found the Cronbach's alpha coefficient of the scale to be 0.91 , and examined its correlation using the State-Trait Anxiety Inventory for the validity of the scale, which found the scores to be 0.39 and 0.89 . Each scale item was rated using a 5 -point Likert scale. The scale scores ranged from from $1=I$ like it very much to $5=I$ don't like it at all. The higher the scores, the higher the levels of dissatisfaction with body conception.

Rosenberg Self-Esteem Scale. The RSES was developed by Rosenberg (1965) and adapted into Turkish by Çuhadaroğlu (1986) and Tuğrul (1994). It is a 4-point Likert-type scale consisting of 10 items with five positive and five negative statements. Total scoring was used because self-esteem is regarded as a one-dimensional concept (Corwyn, 2000). Cronbach's alpha score was considered to indicate the scale reliability, and quite a high value $(0.85)$ was found. For a short time, a 10 -item scale was identified. Items $1,2,4,6$, and 7 were the statements about positive selfevaluation. Scores ranged from 0 to 3 . Items $3,5,8,9$, and 10 were the statements about negative self-evaluation. Total scores ranged from 0 and 30. Cronbach's alpha reliability coefficient was 0.76 in the adaptation study (Çuhadaroğlu, 1986). In the adaptation study, the reliability coefficient score was found to be 0.71 using the test-retest method at 4-week intervals. The higher the score obtained from the scale after the reverse items were converted, the higher the level of self-esteem.

Personal information form. This was a form prepared by the researcher to identify some sociodemographic characteristics of the participants. In this form, the adolescents were asked questions about their age, gender, and whether they had been diagnosed with a psychiatric disorder. Because SHB was a sore spot, personal identifying information excluding age and gender, such as name, class, and student number, were not asked.

\section{Procedure and Data Analyses}

To conduct this research, four high schools in Trabzon were selected and administrative approval was given to conduct the present research. The necessary permits were obtained from the Karadeniz Technical University and the Ministry of National Education. In addition, student parents were informed about this issue.

The researcher administered the measurement tools to the participant groups in a classroom environment. Before the tests were administered, the participants were informed about the aim of the research and in what ways the measurement tools would be answered. Data were analysed using the SPSS 23.0 software package. The Pearson product-moment correlation coefficient, multiple linear regression analysis, and $t$ test were used as the statistical procedures. 


\section{Results}

Of the 263 adolescent participants, 118 exhibited an SHB, and 145 did not exhibit any SHB. The most widely observed SHBs were as follows: prevention of wound healing (wound-excoriation), 58 (49.15\%); scratching a letter, text, or figure on the skin, 42 (35.59\%); intentionally crashing oneself into a firm surface or beating oneself, 36 (30.50\%); hair plucking, 29 (24.57\%); cutting, 18 (15.25\%); biting, 16 (16.10\%); pinching, 13 (11.01\%); clawing, $11(9.32 \%)$; rubbing the body on a firm surface, $10(8.47 \%)$; and self-pricking, $8(6.77 \%)$. The adolescents could select multiple options.

Before the analyses were conducted to test the hypotheses, the researchers examined whether the data were distributed normally or not; the scores showed that they were distributed normally. To determine whether risk-taking behaviours and selfesteem of the adolescents regressed SHB (Section II of ISAS), first, the presence of significant relationships between the variables using the Pearson product-moment correlation coefficient technique and highly significant relationships were observed.

Hypothesis 1: There is a significant relationship between SHB, body image, and self-esteem. Pearson product-moment correlation coefficient results, mean scores and, standard deviations that were calculated to test this hypothesis are shown in Table 1 . The analyses concluded that a highly significant negative relationship $(r=$ $-0.732, p<.001$ ) was observed between the ISAS (Section II) scores and the selfesteem scores of the adolescents who exhibited SHB, and that a highly significant positive relationship $(r=.683, p<.001)$ was observed between the SHB scores and the body image scores. To determine whether self-esteem and body image regressed the SHB or not, a multiple regression analysis was conducted, and the results are shown in Table 2.

\section{TABLE 1}

Correlations for the Relationship Between SHB, Self-Esteem and Body Image

\begin{tabular}{lccc}
\hline & 1 & 2 & 3 \\
\hline 1. SHB & 1 & $-0.732^{* * *}$ & $0.683^{* * *}$ \\
2. SE & & 1 & $-0.562^{* * *}$ \\
3. BI & & 1 \\
\hline
\end{tabular}

Note: ${ }^{* * *} p<.001 . \mathrm{SHB}=$ self-harm behaviour, $\mathrm{SE}=$ self-esteem, $\mathrm{BI}=$ body image.

\section{TABLE 2}

Multiple Regression Analysis

\begin{tabular}{|c|c|c|c|c|c|c|c|c|c|}
\hline Regressor & $B$ & SE & $B$ & $t$ & $p$ & $R$ & $R^{2}$ & $\Delta R^{2}$ & $F$ \\
\hline (Constant) & 2.11 & .038 & & 18.92 & $.003^{* *}$ & .67 & .59 & .61 & 1083.23 \\
\hline SE & -.13 & .012 & -.32 & -21.07 & $.005^{* *}$ & & & & \\
\hline $\mathrm{BI}$ & .021 & .031 & .36 & 29.67 & $.008^{* *}$ & & & & \\
\hline
\end{tabular}

Note: ${ }^{* *} p<.01 . \mathrm{SHB}=$ self-harm behaviour, $\mathrm{SE}=$ self-esteem, $\mathrm{BI}=$ body image. 


\section{TABLE 3}

Results of the $t$ Test for the Difference Between Self-Esteem Levels and Body Images of the Adolescents Who Exhibited SHB and Those Who Did Not

\begin{tabular}{lllllll}
\hline Variable & & $N$ & Average & SD & \multicolumn{1}{c}{$t$} & $p$ \\
\hline SE & Adolescents Who Exhibited SHB & 118 & 14.47 & 4.83 & 24.82 & $0.009^{* *}$ \\
& Adolescents Who Did Not Exhibit SHB & 145 & 21.63 & 5.18 & & \\
BI & Adolescents Who Exhibited SHB & 118 & 92.48 & 11.93 & 31.52 & $0.003^{* * *}$ \\
& Adolescents Who Did Not Exhibit SHB & 145 & 49.54 & 7.29 & & \\
\hline
\end{tabular}

Note: ${ }^{* *} p<.01,{ }^{* * *} p<.001 . \mathrm{SHB}=$ self-harm behaviour, $\mathrm{SE}=$ self-esteem, $\mathrm{BI}=$ body image.

Hypothesis 2: Body image and self-esteem are significant regressors in adolescents. According to the multiple regression analysis results, self-esteem and body image significantly regressed the scores (Section II of ISAS) of the adolescents who exhibited SHB $(F=1083.23, p<.01)$. Furthermore, the original contributions of self-esteem and body image were observed to be significant $(\beta=-0.32, p<.001$; $\beta=.36, p<.001$ ), and according to the beta scores, body image's contribution to the model was higher than that of the self-esteem. For the relevant model, the rate of the total explained variance was $59 \%$.

Hypothesis 3. Female and male adolescents who exhibited SHB had more negative body images and lower levels of self-esteem than those of the adolescents who did not exhibit SHB. The analyses concluded that there was a significant difference between the self-esteem scores $(t=-24.82, p<.01)$ and the body image scores $(t=31.52, p<.001)$ of the adolescents who exhibited SHB and those who did not. The mean self-esteem scores of the adolescents who did not exhibit SHB $(=21.63)$ were significantly higher than those of the adolescents who exhibited SHB (=14.47). The mean body image scores of the adolescents who exhibited SHB $(=92.48)$ were significantly higher than those of the adolescents who did not exhibit SHB $(=49.54)$.

\section{Discussion}

The present study primarily revealed the self-harm behaviours widely exhibited by the adolescents who participated in the study. Most compulsive self-harm behaviours (hair pulling, wound excoriation) were observed in the groups where no psychiatric disorder was reported (Klonsky, Oltmanns, \& Turkheimer, 2003; Oktan, 2014; Parker et al., 2005; Simeon \& Favazza, 2001). Similar results were obtained from this study. The most widely observed SHB among the adolescents was found to be 'prevention of wound healing (wound-excoriation)' $(49.15 \%)$. It can be stated that the research group mainly exhibited compulsive self-harm behaviours. The research group of this study excluded students diagnosed with a psychiatric disorder. Thus, the results of the present study conformed with those of previous studies that included normal populations. Lundh et al. (2007) emphasised the high scores of SHB and reported that the items 'prevention of wound healing' and 'pricking the skin' in their SHB inventory were predominantly selected. Studies 
have shown that individuals exhibited SHB to overcome the pain (Klonsky, 2007; Nock \& Prinstein, 2004). Therefore, it can be stated that adolescents who exhibited SHB were deprived of strategies for effectively overcoming stressful feelings and situations. The research group was located in a rural city in Turkey outside the metropolitan area. However, occurrence rates of SHB obtained in the present research conformed with those of the other studies conducted in the metropolitan cities in Turkey (Lüleci, 2007; Ögel and Aksoy, 2006; Zoroğlu et al., 2003). Thus, it can be stated that the adolescents in this research group who exhibited SHB were deprived of appropriate models through which they could learn to effectively overcome challenging events either at school or in the family rather than in their present environment.

The present research showed that there was a significant negative relationship between SHB and self-esteem, and a significant positive relationship between SHB and body image. It also indicated that self-esteem and body image were significant regressors of SHB. Self-esteem was regarded as one of the most important variables associated with SHB. A low level of self-esteem had the potential to be a risk factor, affecting both mental and physical processes, producing negative results, and exhibiting maladaptive behaviours. Adolescents with low levels of self-esteem exhibited less consistent behaviours than their peers and thus tended to be more exposed to peer pressure (Taylor \& Montgomery, 2007).

The death of one or both parents, history of alcohol addiction in their family, selfesteem, and poverty were reported to be the factors creating susceptibility to SHB (Ystgaard, Reinholdt, Husby, \& Mehlum, 2003). Greydanus and Shek's (2009) study reported that adolescents with low levels of self-esteem were at greater risk of SHB. The personality traits of the adolescents were examined and some characteristics, such as having overwhelmingly negative feelings and self-underestimation, were observed. Many previous studies have indicated that adolescents who exhibit SHB have low levels of self-respect (Brausch \& Gutierrez, 2010; Cawood \& Huprich, 2011; Hawton, Rodham, Evans, \& Weatherall, 2002; Low et al., 2000). Hodgson (2004) found that adolescents who exhibited SHB had higher levels of self-criticism and self-denigration, and lower levels of self-esteem than adolescents who did not exhibit SHB. Further, many adolescents gave reasons such as 'I do not like myself' for their SHB. Lundh et ak. (2007) reported that the adolescents who exhibited SHB had low levels of self-esteem. Also, Aktepe, Çalışkan, and Sönmez (2014) achieved similar results in their study. They found that a low level of selfesteem was an important risk factor for SHB. Increased self-dislike in adolescents supports the notion that $\mathrm{SHB}$ could be a means of punishing oneself and developing self-hatred of one's own body (Claes et al., 2010). When associated with a low level of self-esteem, SHB could express self-criticism in the form of self-punishment (Claes \& Vandereycken, 2007).

The present research showed a significant positive relationship between body image and SHB. Limited numbers of previous studies emphasised the relationship between body image and SHB (Claes, Vandereycken, \& Vertommen, 2003; Muehlenkamp \& Brausch, 2012; Muehlenkamp, Swanson, \& Brausch, 2005). According to Nelson and Muehlenkamp (2012), the first study that examined the relationship between body image and SHB was conducted by Walsh and Rosen (1988), who reported that the adolescents in the clinic sampling group aged from 
15 to 20 had body images that were more negative than those of the adolescents who did not exhibit SHB.

Muehlenkamp et al. (2005) revealed that a negative body image - that is, not liking one's body - did not directly affect SHB, but enhanced the risk of SHB occurrence. Orbach (1996) reported that the relationship between body dissatisfaction and self-destructive behaviours was true for both genders and that the adolescents who exhibited self-destructive behaviours had higher levels of body dissatisfaction than those who did not exhibit self-destructive behaviours (Orbach et al., 2006). Similarly, Ross et al. (2009) reported that the students who exhibited self-destructive behaviours had higher levels of body dissatisfaction than those who did not. Based on all these data, it could be stated that when adolescents encountered problems, those with body dissatisfaction tended to misuse their body more to counteract the trouble that the problems caused.

Positive bodily experiences, attitudes, and feelings underlie the urge toward body protection, which in turn enhances the tendency to engage in supportive selfpreservation. Extremely negative life experiences (e.g., physical or mental trauma) can lead to emotional distress and change an individual's attitudes, feelings, and perceptions related to their body, that in turn results in negative views and attitudes regarding bodily experiences. Such changes, along with the already existing emotional distress, can diminish the likelihood of self-preserving behaviours, subsequently leading to the weakening of the individual's natural shield protecting the body, which then paves the way for self-destructive behaviours (Duggan, Toste, \& Heath, 2013). Orbach (1996) proposed that having negative body attitudes, along with reduced contributions to body image and body protection, can increase a person's tendency toward suicidal behaviour. Orbach argued that individuals with negative body attitudes had a higher tendency to physically harm their bodies because they showed contempt and disrespect for their own bodies and they were disassociated from them (Nelson \& Muehlenkamp, 2012).

Avoiding the negative feelings that accompany a low level of self-esteem, such as feeling one is unimportant and worthless, or failing to use satisfying methods to cope with these strong negative feelings, were among the most significant underlying causes of SHB (Walsh, 2006). The fact that an individual's negative feelings toward themselves regarding the low level of self-esteem and negative body image were found to be associated with SHB was therefore a significant result. SHB had an intermediary role to eliminate or relieve the negative feelings and thoughts, such as guilt, loneliness, self-hatred, self-dislike, and self-deprecation. Thus, an individual's efforts to eliminate negative feelings about themselves or to enhance the level of self-esteem seem extremely important to eliminate or relieve SHB (Oktan, 2014).

The first attempt to self-harm occurs between 13 and 15 years of age and when adolescents first have conflicts with their peers and parents, and come face to face with various stressful experiences $(\mathrm{Ng}, 1998)$. If the first self-harm behaviour in adolescents begins with a repetitious process, it can be a sign that a complete suicide may occur (Joiner, 2002). The adolescence period is very important in terms of the beginning and continuity of the SHB. For this reason, school counsellors should be careful about the SHB statements of students. SHB is regarded as a means by which adolescents demonstrate that they are not able to effectively cope with their problems. For this reason, school counsellors should be sensitive to students' ability 
to acquire knowledge and coping skills and to implement group programs aimed at increasing self-esteem. On the other hand, since body image is especially important for adolescence, it is important for school counsellors to research studies on realistic and positive evaluations of adolescents' bodies and provide information about the body developments and changes during adolescence period, as girls' body image in particular is affected by their self-image. Therefore, school counsellors, as well as providing information, should encourage adolescents' awareness that they are not merely bodies but also have many other valuable qualities that are intrinsic to their self-image.

Recent studies of adolescents with SHB indicate that adolescents need someone they can talk to without being judged at school, and that they have concernes about seeking, labelling, and secrecy. In fact, many of the recent studies on helpseeking patterns among self-harming youth indicate that primary prevention in the schools is essential, and student-reported ideas for preventing self-harm corroborate the importance of using schools and teachers as an initial starting point. Therefore, SHB preventive programs should be based on school personnel. Goals of the schoolbased prevention program are to: (a) increase knowledge of SHB, including warning signs and symptoms; (b) improve attitudes and perceived capability to respond and help refer students or peers who engage in SHB; (c) increase help-seeking behaviours for SHB for peers or self; and (d) decrease acts of SHB among adolescents. A program that can potentially reduce stigma and create an open attitude towards help-seeking is viewed as critical for prevention of SHB by adolescents and may help to alter the subjective norms of adolescents so that seeking professional help becomes more acceptable regardless of the problem (Muehlenkamp, Walsh, \& McDade, 2010).

\section{Limitations and Suggestions for Future Research}

Although the present study is important due to the results it revealed, it had some limitations. First of all, an inadequate number of adolescents participated in the research. More comprehensive studies should be conducted with larger numbers of participants. Moreover, it was assumed that the present study was conducted with the participation of a normal population by asking the adolescents whether they had been diagnosed with a mental disorder, or not. An evaluation should be made using a tool that could measure this situation, rather than relying on self-report. In conclusion, comparative examination of SHB behaviours among normal and clinical populations in SHB studies and comparing the negative body images by SHB types can be useful for future studies.

\section{References}

Aktepe, E., Çalışkan, S., \& Sönmez, Y. (2014). Kendine zarar veren ergenlerin aile işlevlerinin ve benlik saygılarının saptanması: Olgu-kontrol çalışması [Identification of family functions and self-esteem of self-injurious adolescents: A case-control study]. Anadolu Psikiyatri Dergisi, 15, 69-76. doi:10.5455/apd.39823

Andover, M.S., Pepper, C.M., \& Gibb, B.E. (2007). Self-mutilation and coping strategies in a college sample. Suicide and Life-Threatening Behaviour, 37, 238-243. doi:10.1521/suli.2007.37.2.238 
Bildik, T., Somer, O., Kabukcu Basay, B., Basay, O., \& Ozbaran, B. (2012). Kendine zarar verme davranışı değerlendirme envanterinin Türkçe formunun geçerlik ve güvenilirlik çalışması [The validity and reliability study of the Turkish version of self-injurious behaviour assessment inventory]. Türk Psikiyatri Dergisi, 23, 49-57. doi:10.5080/u6901

Brausch, A.M., \& Gutierrez, P.M. (2010). Differences in non-suicidal self-injury and suicide attempts in adolescents. Journal of Youth and Adolescence, 39, 233-242. doi:10.1007/s10964-009-9482-0

Brausch, A.M., Decker, K.M., \& Hadley, A.G. (2011). Risk of suicidal ideation in adolescents with both self-asphyxial risk-taking behaviour and non-suicidal self-injury. Suicide and Life-Threatening Behaviour, 41, 424-434. doi:10.1111/j.1943-278X.2011.00042.x

Brunner, R., Parzer, P., Haffner, J., Steen, R., Roos, J., Klett, M., \& Resch, F. (2007). Prevalence and psychological correlates of occasional and repetitive deliberate selfharm in adolescents. Archives of Pediatric Adolescent Medicine, 161, 641-649. doi:10.1001/archpedi.161.7.641

Cash, T.F. (2002). A negative body image: Evaluating epidemiological evidence. In T.F. Cash \& T. Pruzinsky (Eds.), Body image: A handbook of theory (pp. 269-286). New York, NY: Guilford Press.

Cawood, C.D., \& Huprich, S.K. (2011). Late adolescent nonsuicidalself-injury: The roles of coping style, self-esteem, and personality pathology. Journal of Personality Disorders, 25, 765-781. doi:101521pedi2011256765

Claes, L., Vandereycken, W., \& Vertommen, H. (2003). Eating disordered patients with and without self-injuriousbehaviours: a comparison of psychopathological features. European Eating Disorders Review, 11, 379-396. doi:10.1002/erv.510

Claes, L., Houben, A., Vandereycken, W., Bijttebier, P., \& Muehlenkamp, J.J. (2010). The association between non-suicidal self-injury, self-concept and acquaintance with self-injurious peers in a sample of adolescents. Journal of Adolescence, 33, $775-778$.

Claes, L., \& Vandereycken, W. (2007). Is there a link between traumatic experiences and self-injurious behaviours in eating-disordered pstients? Eating Disorders, 15, 305-315. doi:10.1080/10640260701454329

Claassen, C.A., Trivedi, M., Shimizu, I. Stewart, S., Larkin, G.L., \& Litovitz, T, (2006). Epidemiology of nonfatal deliberate self-harm in the United States as described in three medical databases. Suicide and Life-Threatening Behaviour, 36, 192-212. doi:10.1521/suli.2006.36.2.192

Corwyn, R.F. (2000). The factor structure of global self-esteem among adolescents and adults. Journal of Research in Personality, 34, 357-379.

Çuhadaroğlu, F. (1986). Adolesanlarda benlik saygısı [Adolescents' self-esteem] (Unpublished masters thesis). Hacettepe University, Ankara, Turkey.

Duggan, J.M., Toste, J.R., \& Heath, N.L. (2013). An examination of the relationship between body image factors and non-suicidal self-injury in young adults: The mediating influence of emotion dysregulation. Psychiatry Research, 206, 256-264.

Greydanus, D.E., \& Shek, D. (2009). Deliberate self-harm and suicide in adolescents. Keio Journal of Medicine, 58, 144-151. doi:10.2302/kjm.58.144

Gratz, K.L., Conrad, S.D., \& Roemer, L. (2002). Risk factors for deliberate selfharm among college students. American Journal of Orthopsychiatry, 72, 128-140. doi:10.1037/0002-9432.72.1.128 
Hawton, K., Rodham, K., Evans, E., \& Weatherall, R. (2002). Deliberate self-harm inadolescents: Self-report survey in schools in England. British Medical Journal, 325, 1207-1211. doi:10.1136/bmj.325.7374.1207

Hodgson, S. (2004). Cutting through the silence: A sociological construction of selfinjury. Sociological Inquiry, 74, 162-179. doi:10.1111/j.1475-682X.2004.00085.x

Hovardaoğlu, S. (1993). Vücut Algısı Ölçeği [Body Perception Scale]. Psikiyatri, Psikoloji ve Psikofarmakoloji (3P) Dergisi,1, 26.

Joiner, T.E. (2002). The trajectory of suicidal behavior over time. Suicide and LifeThreatening Behavior, 32, 33-41.

Kemperman, I., Russ, M.J., Clark, W.C., Kakuma, T., Zanine, E., \& Harrison, K. (1997). Pain assessment in self-injurious patient with borderline personality disorder using signal detection theory. Psychiatry Research, 70, 175-183. doi:10.1016/S0165-178(97)00034-6

Klonsky, E.D. (2007). The functions of deliberate self-injury: A review of the evidence. Clinical Psychology Review, 27, 226-239. doi:10.1016/jcpr.2006.08.002

Klonsky, E.D., \& Glenn, C.R. (2009). Assessing the functions of non-suicidal self-injury: Psychometric properties of the Inventory of Statements about SelfInjury (ISAS). Journal of Psychopathology and Behavioral Assessment, 31, 215-219.

Klonsky, E.D., Oltmanns, T.F., \& Turkheimer, E. (2003). Deliberate self-harm in a nonclinical population: Prevalence and psychological correlates. American Journal of Psychiatry, 160, 1501-1508. doi:10.1176/appi.ajp.160.8.1501

Laye-Gindhu, A. \& Schonert-Reichl, K. (2005). Nonsuicidal self-harm among community adolescents: Understanding the 'whats' and 'whys' of self-harm. Journal of Youth and Adolescence, 34, 447-57. doi:10.1007/s10964-005-7262-z

Low, G., Jones, D., MacLeod, A., Power, M., \& Duggan, C. (2000). Childhood trauma, dissociation and self-harming behaviour: A pilot study. British Journal of Medical Psychology, 73, 269-278. doi:10.1348/000711200160363

Lundh, L.G., Karim, J., \& Quilisch, E. (2007). Deliberate self-harm in 15year-old adolescents: A pilot study with a modified version of the deliberate self-harm inventory. Scandinavian Journal of Psychology, 48, 33-41. doi:10.1111/j.1467-9450.2007.00567.x

Lüleci, S. (2007). Kendini yaralama davranışı olan ergenlerin psikiyatrik ve sosyokültürel özellikleri [Psychiatric and socio-cultural characteristics of adolescents with self-injurious behaviour] (Unpublished masters thesis). Sağlık Bakanlığı University, İstanbul, Turkey.

Muehlenkamp, J.J., \& Brausch, A.M. (2012). Body image as a mediator of non-suicidal self-injury in adolescents. Journal of Adolescence, 35, 1-9. doi:10.1016j/adolescence. 2011.06.010

Muehlenkamp, J.J., Walsh, B.W., \& McDade, M. (2010). Preventing non-suicidal selfinjury in adolescents: The signs of self-injury program. Journal of Youth Adolescence, 39, 306-314. doi:10.1007/s10964-009-9450-8

Muehlenkamp, J.J., Swanson, J.D., \& Brausch, A.M. (2005). Self-objectification, risk taking, and self-harm in college women. Psychology of Women Quarterly, 29, 2432. doi:10.1111/j.1471-6402.2005.00164.x

Nelson, A., \& Muehlenkamp, J.J. (2012). Body attitudes and objectification in nonsuicidal self-injury: Comparing males and females. Archives of Suicide Research, 16, 1-12. doi:10.1080/13811118.2012.640578 
$\mathrm{Ng}$, G. (1998). Everything you need to know about self-mutilation: A helping book for teens who hurt themselves. New York, NY: Rosen Publishing Group.

Nock, M.K., \& Prinstein, M.J. (2004). A functional approach to the assessment of selfmutilative behaviour. Journal of Consulting and Clinical Psychology, 72, 885-890. doi: 10.1037/0022-006X.72.5.885

Oktan, V. (2014). A characterization of self-injurious behaviour among Turkish adolescents. Psychological Reports, 115, 645-654. doi:10.2466/16.02.PR0.115c25z5

Orbach, I. (1996). The role of the body experience in self-destruction. Clinical Child Psychology and Psychiatry, 1, 607-619. doi:10.1177/1359104596014012

Orbach, I., Gilboa-Schectman, E., Sheffer, A., Meged, S. Har-Even, S., \& Stein, D. (2006). Negative bodily self in suicide attempters. Suicide and Life-Threatening Behaviour, 36, 136-153. doi:10.1521/suli.2006.36.2.136

Ögel, K., \& Aksoy, A. (2006). Kendine Zarar Verme Davranışı Raporu [Self-injury Behaviour Report]. Yeniden Yayın, 18, İstanbul.

Parker, G., Malhi, G., Mitchell, P., Kotze, B., Wilhelm, K., \& Parker, K. (2005). Selfharming in depressed patients: Pattern analysis. Australian and New Zealand Journal of Psychiatry, 39, 899-906. doi:10.1111/j.1440-1614.2005.01662.x

Rosenberg, M. (1965). Society and the adolescent self-image. Princeton, NJ: Princeton University Press.

Ross, S., Heath, N.L., \& Toste, J.R. (2009). Non-suicidal self-injury and eating pathology in high school students. American Journal of Orthopsychiatry, 79, 83-92. doi:10.1037/a00014826

Rodham, K., Hawton, K., \& Ewans, E. (2004). Reasons for deliberate self-harm: comparison of self-poisoners and self-cutters in a community sample of adolescents. Journal of The American Academy of Child \& Adolescent Psychiatry, 43, 80-87. doi:10.1097/00004583-200401000-00017

Secord, P.F., \& Jourard, S.M. (1953). The appraisal of body-cathexis: Body-cathexis and the self. Journal of Consulting Psychology, 18, 343-347.

Shaffer, D., \& Jacobson, C. (2009). Proposal to the DSM-V childhood disorder and mood disorder work groups to include non-suicidal self-injury (NSSI) as a DSM-V disorder. Washington, D.C.: American Psychiatric Association.

Simeon, D., \& Favazza, A.R. (2001). Self-injurious behaviours: Phenomenology and assessment. In D. Simeon \& E. Hollander (Eds.), Sef-injurious behaviours: Assessment and treatment (pp. 1-289). Washington, D.C.: American Psychiatric Press.

Skegg, K. (2005). Self-harm. The Lancet, 366, 1471-1483. doi:10.1016/S0140-6736(05)67600-37

Steinberg, L. (2013). Adolescent. Figen Çok (Ed.). Ankara, Turkey: İmge Kitabevi

Svec, H.J., Vandenburg, G., Jack, M., Toland, D., \& Barerra, F.J. (1989). Familiarity, proximity and self-injurious behaviours. Psychological Reports, 65, 801-802. doi:10.2466/pr0.1989.65.3.801

Taylor, T.L., \& Montgomery, P. (2007). Can cognitive-behavioural therapy increase self-esteem among depressed adolescents? A systematic review. Children and Youth Services Review, 29, 823-839. doi:10.1016/j.childyouth.2007.01.010

Tresno, F., Ito, Y., \& Mearns, J. (2012). Self-injurious behaviour and suicide attempts among Indonesian college students. Death Studies, 36, 627-639. doi:10.1080/07481 187.2011 .604464 
Timson, D., Priest, H., \& Clark-Carter, D. (2012). Adolescents who self-harm: Professional staff knowledge, attitudes and training needs. Journal of Adolescence, 35, 1307-1314. doi:10.1016/j.adolescence.2012.05.001

Tuğrul, C. (1994). Alkoliklerin çocuklarının aile ortamındaki stres kaynakları, etkileri ve stresle başa çıkma yolları. Türk Psikoloji Dergisi, 9, 54-73.

Turp, M. (1999). Encountering self-harm in psychotheraoy and councelling practice. British Journal of Psychotherapy, 15, 306-321. doi:10.1111/j.1752-0118.1999.tb00455.x

Walsh, B.W. (2006). Treating self-injury: A practical guide. New York, NY: Guilford Press.

Walsh, B., \& Rosen, P. (1988). Self-mutilation: Theory, research and treatment. New York, NY: Guilford Press.

Webb, L. (2002). Deliberate self-harm in adolescence: a systematic review of psychological and psycho social factors. Journal of Advanced Nursing, 38, 235-244. doi:10.1046/j.1365-2648.2002.02174.x

Ystgaard, M., Reinholdt, N.P., Husby, J., \& Mehlum, L. (2003). Deliberate self-harm in adolescents. Tidsskrift for den Norske Laegeforening, 123, 2241-2245.

Zoroglu, S.S., Tuzun, U., Sar, V., Tutkun, H., Savas, H.A., Ozturk, M., .. . Kora, M.E. (2003). Suicide attempt and self-mutilation among Turkish high school students in relation with abuse, neglect, and dissociation. Psychiatry and Clinical Neurosciences, 57, 119-126. 